\title{
PENGARUH EKUITAS MEREK DAN WORD OF MOUTH TERHADAP KEPUTUSAN NASABAH UNTUK MENABUNG DI BANK BRI CABANG S. PARMAN BENGKULU
}

\author{
Veny Puspita \\ Universitas Prof Dr. Hazairin, SH \\ venypuspita2288@gmail.com
}

\begin{abstract}
Abstrak
The purpose of this study was to determine the composition of brand equity and word of mouth for customer decisions regarding deposit accounts at BRI Bank Parman Bengkulu. The nature of this research is associative. In accordance with the nature of this study, two types of qualitative data and quantitative data. Research data sources: primary data and secondary data. Respondents in this study are those who have savings at Bank BRI Parman Bengkulu. Data collection techniques using a questionnaire and the data obtained were analyzed using. Research Results The brand equity variable and Word of Mouth has influence both partial and simultaneous on the customer's decision to save. It should be like that
\end{abstract}

Keywords: Ekuitas merek,word of mouth, keputusan menabung

\section{PENDAHULUAN}

Perkembangan Industri perbankan terus dihadapkan dengan persaingan yang kompetitif untuk menarik pangsa pasar.Setiap usaha perbankan harus terus berupaya untuk mengoptimalkan setiap sumber daya yang mereka miliki.Di era globalisasi saat ini banyaknya pilihan produk perbankan yang muncul di pasaran membuat para konsumen menjadi kesulitan dalam menentukan keputusannya untuk memilih perbankan mana yang tepat untuknya.Perbankan sudah menjadi bagian dari kehidupan masyarakat dan hampir seluruh lapisan masyarakat menggunakan sektor jasa ini.

Perusahaan perbankan dituntut untuk memberikan layanan yang optimal kepada konsumennya guna membangun sebuah citra perusaahn yang positif, untuk mengatasi hal tersebut perusahaan perbankan harus berupaya untuk membangun ekuitas merek. Citra perusahaan akan membantu para konsumen dalam memahami sebuah produk dan jasa yang ditawarkan perusahaan perbankan tersebut. Kesan merek yang baik akan muncul dari pengetahuan dan pengalaman nasabah yang pernah menggunakan produk atau jasa dari suatru perbankan. Arya Nugraha et al., (2016 : 2193). Untuk memperkuat persaingan antar perusahaan perbanakan, maka perusahaan perbankan harus memperkuat ekuitas mereknya.

Ekuitas merek adalah nilai yang ditentukan oleh konsumen pada suatu merek di atas dan di luar karakteristik/ atribut fungsional dari produk. Supranto dan Limakrisna, (2011:132). Ekulias merek akan mempengaruhi kepercayaan nasabah atau konsumen untuk mengambil keputusan menabung, baik karena ada pengalaman dari masa lalu dalam menggunakan merek tersebut atau memiliki kedekatan dengan merek dan karakteristiknya.

Kesan yang baik terhadap sebuah merek akan memunculkan word of mouth yang positif begitu pula sebaliknya kesan yang buruk terhadap sebuah merek akan memunculkan word of mouth yang negatif. Word of mouth adalah komunikasi 
elektronik,tertulisdanlisanantarmasyarakatberhubungan pengalaman / keunggulan menggunakanproduk atau jasa. Kotler dan Keller., (2016:174)

Word of mouth memiliki peran yang penting dalam memediasi citra bank terhadap keputusan konsumen atau nasabah. Berdasarkan latar belakang di atas, maka peneliti tertarik untuk mengangkat judul pengaruh Ekuitas Merek dan Word of Mouth terhadap keputusan nasabah untuk menabung di Bank BRI Cabag S. Parman Bengkulu

\section{LANDASAN TEORI}

\section{Ekuitas Merek}

"Ekuitas merek (brand equity) adalah seperangkat asosiasi dan perilaku yang dimiliki oleh pelanggan merek, anggota saluran distribusi, dan perusahaan yang memungkinkan suatu merek mendapatkan kekuatan, daya tahan, dan keunggulan yang dapat membedakan dengan merek pesaing".

Menurut Kotler dan Keller., (2009: 265) "Ada lima komponen atau kunci dari ekuitas merek" yaitu diferensiasi, energi, harga diri, pengetahuan mengukur kadar keakraban dan keintiman konsumen dengan merek. Deferensiasi, energy dan relevansi di gabungkan untuk menentukan kekuatan merek yang menggerakan. Pilar ini menunjukkan nilai masa depan dari merek. harga diri dan pengetahuan bersama-sama menciptakan reputasi merek, yang lebih merupakan "kartu laporan" tentang kinerja dari masa lalu.Ada tiga penggerak ekuitas merek yaitupilihan awal untuk elemen atau identitas merek yang membentuk merek seperti nama merek, URL, logo, lambang, karakter, jutru bicara, selogan, lagu, kemasan, papan. Produk dan jasa serta semua kegiatan pemasaran dan program pemasaran pendukung yang menyertainya.Asosiasi lain yang diberikan secara tidak langsung ke merek dengan menghubungkan merek tersebut dengan beberapa entitas lain (orang, tempat atau barang).

\section{Word Of Mouth (WOM)}

Menurut Kotler dan Keller.,(2016:174) “Word Of Mouth (WOM) adalah komunikasi elektronik, tertulis dan lisan antar masyarakat berhubungan pengalaman/ keunggulan menggunakan produk atau jasa". Menurut Kotler dan Kelle, (2016 :177) "manfaat Word of Mouth adalah untuk meyakinkan keseseorang dengan tidak mengeluarkan biaya yang besar". Beberapa hal yang dapat digunakan sebagai indikator dalam menentukan apakah word of mouth communication tersebut berhasil atau tidak. Ada lima karakteristik WOM, menurut Buttle, (2010:34) yang terdiri dari valence, focus, timing, solicitation, intervention.

\section{KeputusanPembelian.}

Keputusan pembelian adalah proses keputusan pembeli akan membeli atau tidak membeli di peroleh dari kegiatan sebelumnya. "Keputusan pembelian diartikan sebagai proses penyelesaian masalah atas akan membeli atau tidak membeli di peroleh dari kegiatan sebelumnya". Messauri, (20018: 141). Tahap-tahap keputusan pembelian Handoko., (2012 : 107) terdiri dari tahap pengenalan masalah,pencarian informasi, evaluasi alternative, keputusan membeli, perilaku setelah pembelian setelah membeli produk. 


\section{Kerangka Pikir}

Gambar 1

Kerangka Pikir

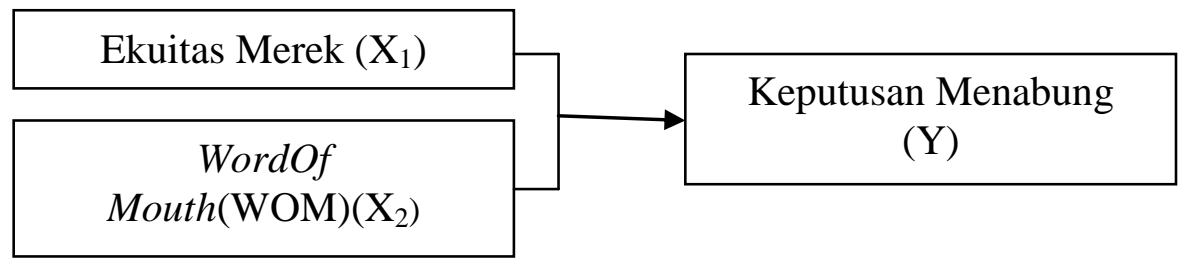

Dari kerangka pemikiran diatas, menunjukkan adanya pengaruh Ekuitas Merek $\left(\mathrm{X}_{1}\right)$, Word Of Mouth $\left(\mathrm{X}_{2}\right)$ terhadap keputusan menabung $(\mathrm{Y})$ baik secara simultan ataupun parsial.

\section{Hipotesis}

Adapun hipotesis dalam penelitian ini :

H1 : Diduga Ekuitas merek mempunyai pengaruh terhadap keputusan menabungdi Bank BRI S Parman Bengkulu

H2 : Diduga word of mouth mempunyai pengaruh terhadap keputusna menabung di Bank BRI S Parman bengkulu

H3 : Diduga Ekuitas merek dan word of mouthmempunyai pengaruh terhadap keputusan menabung di Bank BRI S Parman Bengkulu

\section{METODOLOGI}

Sifat penelitian dalam penelitian ini adalah penelitian asosiatif. Menurut sifatnya penelitian ini terdapat dua jenis data yakni data kualitatif dan data kunatitatif. Sumber Data penelitian ini berupa data primer. Penelitian ini data primer bersumber dari penyebaran kuesioner secara langsung kepada Nasabah Bank BRI S. Parman Bengkulu yang telah memiliki rekening tabungan di Bank BRI S Parman Bengkulu dan hasil dari data tersebut dikumpulkan dan diolah sendiri oleh penulis. Selanjutnya penulis menggunakan data sekunder berupa studi kepustakaan.

Populasi dari penelitian ini adalah seluruh nasabah yang memiliki rekening tabungan pada Bank BRI S Parman Bengkulu. Adapun pedoman yang digunakan dalam menentukan besaran sampel, apabila populasi berukuran besar dan jumlahnya tidak diketahui, maka digunakan rumus sebagai berikut :

$$
n=\frac{Z^{2}}{4(M o e)^{2}}
$$

Dengan menggunakan margin of error sebesar 10\%, maka jumlah sampel minimal yang dapat diambil dalam penelitian ini adalah sebagai berikut :

$$
\begin{aligned}
n & =\frac{1,96^{2}}{4(0,1)^{2}} \\
& =96,04
\end{aligned}
$$

Jumlah sampel penelitian ini sebanyak 96 responden. Untuk mengantisipasi kuesioner yang tidak dapat dipakai atau diolah maka sampel yang akan digunakan 
sebanyak 100 orang. Cara penarikan sampel yang digunakan dalam penelitian ini adalah dengan purposive sampling yaitu "penulis menggunakan pertimbangan sendiri dengan cara sengaja dalam memilih anggota populasi yang dianggap dapat memberikan informasi yang diperlukan oleh penulis" (Sugiyono, 2004). Responden yang dipilih oleh penulis dalam penelitian ini adalah nasabah yang memiliki rekening tabungan pada Bank BRI S Parman Bengkulu.

Adapun teknik dan alat pengumpulan data dalam penelitian ini berupa data lapangan dan data kepustakaan. Metode Analisis Data menggunakan Uji instrumen, Uji Asumsi Klasik, Uji Statistik

\section{HASILDAN PEMBAHASAN}

\section{Uji Instrumen}

a. Uji Validitas

Berikut ini hasil uji validitas yang di olah dengan menggunakan SPSS. Hasil lengkapnya tersaji pada tabel 1 berikut ini :

Tabel 1

Hasil Uji Validitas

\begin{tabular}{|c|c|c|c|}
\hline Item & $\mathbf{r}_{\text {hitung }}$ & $\mathbf{r}_{\text {tabel }}$ & Status \\
\hline$(\mathrm{X} 1) 1$ & 0,785 & 0.1966 & Valid \\
\hline$(\mathrm{X} 1) 2$ & 0,900 & 0,1966 & Valid \\
\hline$(\mathrm{X} 1) 3$ & 0,628 & 0,1966 & Valid \\
\hline$(\mathrm{X} 1) 4$ & 0,890 & 0,1966 & Valid \\
\hline$(\mathrm{X} 2) 1$ & 0,730 & 0,1966 & Valid \\
\hline$(\mathrm{X} 2) 2$ & 0,730 & 0,1966 & Valid \\
\hline$(\mathrm{X} 2) 3$ & 0,690 & 0,1966 & Valid \\
\hline$(\mathrm{X} 2) 4$ & 0,663 & 0,1966 & Valid \\
\hline$(\mathrm{Y}) 1$ & 0,635 & 0,1966 & Valid \\
\hline$(\mathrm{Y}) 2$ & 0,635 & 0,1966 & Valid \\
\hline$(\mathrm{Y}) 3$ & 0,628 & 0,1966 & Valid \\
\hline$(\mathrm{Y}) 4$ & 0,607 & 0,1966 & Valid \\
\hline
\end{tabular}

Tabel 1 menyatakan bahwahasil item pernyataan untuk variabel X1 (ekuitas merek), $\mathrm{X} 2$ (word of mouth) dankeputusan menabung dinyatakan valid karena semua nilai $\mathrm{r}_{\text {hit }}$

$>r_{\text {tabel }}$ sehingga semua variabel layak untuk digunakan dalam penelitian ini.

b. Uji Reabilitas

Tabel 2

Hasil Uji Reliabilitas

\begin{tabular}{|l|c|c|c|}
\hline \multicolumn{1}{|c|}{ Variabel } & Cronbach's Alpha & Taraf signifikan & Status \\
\hline Ekuitas Merek & 0,816 & 0.6 & Reliabel \\
\hline Word of Mouth & 0,779 & 0.6 & Reliabel \\
\hline Keputusan menabung & 0,738 & 0.6 & Reliabel \\
\hline
\end{tabular}

Tabel 2 menyatakan bahwa uji reabilitas pada tiap-tiap variabel menunjukkan bahwa nilai Cronbach Alphalebih besar dari taraf signifikan $60 \%(0,6)$, sehingga di sempulkan variabel dalam penelitian ini reliable. 


\section{Uji Asumsi Klasik}

a. Uji Heterokedastisitas

Gambar 2

Hasil uji heterokedastisitas

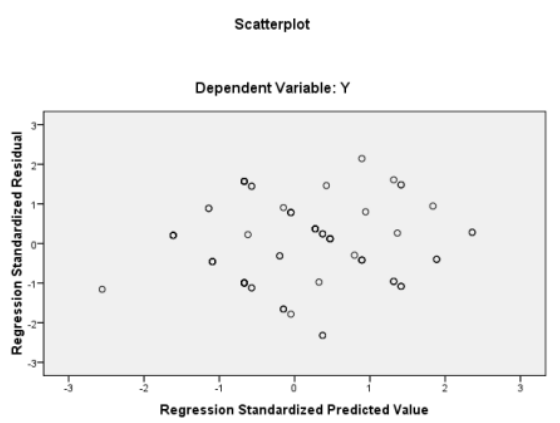

Gambar 2 diatas dapat di ketahui bahwa terjadi heterokedastisitas sebab ada pola yang jelas dengan titik-titik menyebar di atas dan di bawah 0 pada sumbu Y, sehingga dapat dikatakan uji heteroskedastisitas tidak terpenuhi, sehingga analisis berikutnya dapat dilanjutkan.

b. Uji Multikolinieritas

Tabel 3

Hasil uji multikolinieritas

Coefficients $^{\mathrm{a}}$

\begin{tabular}{|l|r|r|}
\hline \multirow{2}{*}{ Model } & \multicolumn{2}{|c|}{ Collinearity Statistics } \\
\cline { 2 - 3 } & Tolerance & \multicolumn{1}{|c|}{ VIF } \\
\hline 1 (Constant) & & \\
X1 & .988 & 1.012 \\
X2 & .988 & 1.012 \\
\hline
\end{tabular}

a. Dependent Variable: Y

Tabel 3 diatas diketahui besarnya nilai VIF (Variance Inflation Factor) variabel Ekuitas merek dan Word Of Mouth sebesar 1,012, maka dari nilai VIF masing-masing Variabel Independent tersebut dinyatakan tidak terjadi multikolinieritas pada persamaan ini karena nilai VIF $<10$.

\section{Uji Statistik}

a. Regresi Linier Berganda

Tabel 4

Analisis regresi

Coefficients $^{\mathrm{a}}$

\begin{tabular}{|ll|r|r|r|}
\hline \multirow{2}{*}{ Model } & \multicolumn{2}{|c|}{$\begin{array}{c}\text { Unstandardized } \\
\text { Coefficients }\end{array}$} & $\begin{array}{c}\text { Standardized } \\
\text { Coefficients }\end{array}$ \\
\cline { 2 - 5 } & \multicolumn{1}{|c|}{ B } & Std. Error & \multicolumn{1}{c|}{ Beta } \\
\hline 1 & (Constant) & .076 & 1.388 & \\
& X1 & .517 & .051 & .641 \\
X2 & .468 & .055 & .536 \\
\hline
\end{tabular}

a. Dependent Variable: $\mathrm{Y}$ 
Tabel 4 di atas diperoleh suatu persamaan regresi sebagai berikut:

$$
\begin{aligned}
& \mathrm{Y}=\mathrm{a}+\mathrm{b} 1(\mathrm{X} 1)+\mathrm{b} 2(\mathrm{X} 2) \\
& \mathrm{Y}=0,076+0,517(\mathrm{X} 1)+0,468(\mathrm{X} 2)
\end{aligned}
$$

Dimana:

$\mathrm{a}=0,076$ artinya jika Ekuitas Merek $\left(\mathrm{X}_{1}\right)$ dan WordOfMouth $\left(\mathrm{X}_{2}\right)$ sama dengan nol, maka nilai Keputusan menabung (Y) sebesar 0,076 poin.

$\beta_{1}=0,517$, koefisien regresi b1 Ekuitas merek (X1) sebesar 0,517, menyatakan setiap kenaikan satusatuanEkuitas merek $\left(\mathrm{X}_{1}\right)$, maka akan menaikkanKeputusan menabung (Y) sebesar 0,517 poin. Dengan asumsi WordOfMouth $\left(\mathrm{X}_{2}\right)$ konstan.

$\beta_{2}=0,468$, koefisien regresi b2 WordOfMouth $(\mathrm{X} 2)$ sebesar 0,468 , menyatakan setiap kenaikan satu satuanWordOfMouth $\left(\mathrm{X}_{2}\right)$, maka akan menaikkankeputusan menabung (Y) sebesar 0,468 poin. Dengan asumsi Ekuitas Merek $\left(\mathrm{X}_{1}\right)$ konstan.

b. Korelasi berganda

Hasil perhitungan korelasi berganda adalah sebagai berikut :

Tabel 5

Analisis korelasi berganda

\begin{tabular}{|l|c|r|r|r|}
\hline Model & R & R Square & Adjusted R Square & Std. Error of the Estimate \\
\hline 1 & $.789^{\mathrm{a}}$ & .623 & .615 & .78047 \\
\hline
\end{tabular}

a. Predictors: (Constant), X2, X1

b. Dependent Variable: Y

Tabel 6

Kekuatan Koefisian Korelasi

\begin{tabular}{|l|l|l|}
\hline 0 & $:$ & Tidak ada korelasi \\
\hline $0,00-0,25$ & $:$ & Korelasi sangat lemah \\
\hline $0,25-0,50$ & $:$ & Korelasi cukup \\
\hline $0,50-0,75$ & $:$ & Korelasi kuat \\
\hline $0,75-0,99$ & $:$ & Korelasi sangat kuat \\
\hline 1 & $:$ & Korelasi sempurna \\
\hline
\end{tabular}

Pada table 6 menunjukkan bahwa koefesien korelasi $(\mathrm{R})=0,789$, ini berarti hubungan antara variabel ekuitas merek (X1) dan word of mouth (X2), terhadap keputusan menabung (Y) adalah sangat kuat.(0.75 - 0.99)

c. Koofisien Determinasi

Hasil perhitungan tabel 5 diperoleh besarnya koefisien determinasi ( $\mathrm{R}^{2} /$ Rsquare) adalah 0,623. Hal ini menyatakan 62,3\% keputusan menabung (Y) dapat dijelaskan oleh ekuitas merek (X2) dan word of mouth (X2), sisanya 37,7\% disebabkan oleh variabel lain yang tidak termasuk diluar model. 
d. Uji Hipotesis

1. Uji t

Tabel 7

Uji t

Coefficients $^{\mathbf{a}}$

\begin{tabular}{|l|r|r|r|r|r|}
\hline \multirow{2}{*}{ Model } & \multicolumn{2}{|c|}{ Unstandardized Coefficients } & Standardized Coefficients & & \\
\cline { 2 - 6 } & $\mathrm{B}$ & Std. Error & Beta & \multicolumn{1}{c|}{$\mathrm{t}$} & Sig. \\
\hline 1 (Constant) & .076 & 1.388 & & .054 & .957 \\
X1 & .517 & .051 & .641 & 10.221 & .000 \\
X2 & .468 & .055 & .536 & 8.542 & .000 \\
\hline
\end{tabular}

a. Dependent Variable: Y

a. Uji koefisien regresi untuk $\beta_{1}$ (Ekuitas merek )

Hasil analisis didapat nilai $t_{\text {hitung }}$ sebesar 10,221. sedangkan nilai $t_{\text {tabel }}$ dengan confidence level $95 \%$ sebesar 1,985, $\mathrm{t}_{\text {tabel }}$ sebesar 1,997 $<\mathrm{t}_{\text {hitung }} 10,221$ dari hasil tersebut keputusannya yang dapat diambil yaitu menolak $\mathrm{H}_{\mathrm{o}}$ dan menerima $\mathrm{H}_{\mathrm{a}}$, maka ekuitas merek berpengaruh terhadap keputusan menabung yang artinya jika variabel ekuitas merek naik maka di ikuti dengan naiknya variabel keputusan menabung

b. Uji koefisien regresi untuk $\beta_{2}$ (Word Of Mouth)

Penujian nilai $t_{\text {hitung }}$ sebesar 8,542 , sedangkan nilai $t_{\text {tabel }}$ dengan confidence level $95 \%$, sebesar $1,985, \mathrm{t}_{\text {tabel }}$ sebesar $1,997<\mathrm{t}_{\text {hitung }} 8,542$ dari hasil tersebut keputusannya yang dapat diambil yaitu menolak $\mathrm{H}_{\mathrm{o}}$ dan menerima $\mathrm{H}_{\mathrm{a}}$, maka variabelWord of Mouth berpengaruh terhadap keputusan menabung yang artinya jika variabel Word of Mouth naik maka di ikuti dengan naiknya variabel keputusan menabung.

2. Uji f

Tabel.8

Uji f

\begin{tabular}{|l|r|r|r|c|c|}
\hline Model & Sum of Squares & Df & Mean Square & F & Sig. \\
\hline Regression & 97.554 & 2 & 48.777 & 80.075 & .000 \\
Residual & 59.086 & 97 & .609 & & \\
Total & 156.640 & 99 & & & \\
\hline
\end{tabular}

a. Predictors: (Constant), X2, X1

b. Dependent Variable: Y

Perhitungan data yang terlihat pada tabel 8 di ketahui bahwa $\mathrm{F}_{\text {hitung }}$ sebesar 80,075 sedangkan $F_{\text {tabel }}$ dengan taraf signifikan 5\% sebesar 3,09, sehingga dapat di simpulkan variabel ekuitas merek dan word of mouth secara bersama-sama mempengaruhi variabel keputusan menabung. 


\section{Pembahasan}

1. Pengaruh ekuitas merek terhadap keputusan nasabah untuk menabung di Bank BRI cabang S. Parman Bengkulu

Ekuitas Merek merupakan penyusunan persepsional, persepsi konsumen, yang memberi nilai tambah untuk produk bermerek (Rodrigues, 2016). Ekitas merek tidak begitu saja terjadi, ekuitas merek diciptakan secara hati-hati dan harus di dukung oleh pemasaran yang kuat, menyenangkan dan terikat dengan konsumen yang khas dan berpengalaman dengan merek tertentu.

Hasil penelitian dari uji statistik yang dilakukan, dapat diketahui bahwa ekuitas merek memiliki pengaruh yang signifikan terhadap keputusan menabung tersaji dalam tabel 7 , dimana di peroleh $t_{\text {tabel }} 1,997<t_{\text {hitung }} 10,221$ dari hasil tersebut keputusan yang dapat diambil yaitu menolak $\mathrm{H}_{\mathrm{o}}$ dan menerima $\mathrm{H}_{\mathrm{a}}$, maka ekuitas merek berpengaruh terhadap keputusan menabung. Penelitian ini menggambarkan semakin meningkat nilai ekuitas merek, maka keputusan menabung pada BRI S Parman semakin meningkat, untuk meningkatkan jumlah minat nasabah untuk menabung dan setia menggunakan jasa perbankan pada BRI S. Parman Bengkulu, maka bank harus selalu membangun pikiran positif nasabah sehingga nasabah dalam berfikir, merasa dan bertindak menjadi tetap setia dan loyal terhadap perusahaan perbankan ini. Ekuitas merek yang melekat dibenak para nasabah ini muncul dari apa yang mereka pelajari, rasakan, lihat dan dengar tentang Bank BRI dari waktu ke waktu.

\section{Pengaruh word of mouth terhadap keputusan nasabah untuk menabung di}

\section{Bank BRI cabang s. Parman Bengkulu}

Word of mouth (WOM) dikenal dengan istilah komunikasi dari mulut ke mulut. Dari hasil penelitian di ketahui bahwa $t_{\text {tabel }}$ sebesar 1,997 $<t_{\text {hitung }} 8,542$ dari hasil tersebut keputusannya yang dapat diambil yaitu menolak $\mathrm{H}_{\mathrm{o}}$ dan menerima $\mathrm{H}_{\mathrm{a}}$, maka variabel Word of Mouth berpengaruh terhadap keputusan menabung, hal tersebut mengandung arti bahwa jika nilai variabel word of mouth meningkat, maka akan mendorong meningkatnya jumlah minat menabung pada Bank BRI S Parman Bengkulu. word of mouth menjadi media yang paling kuat dalam mengkomunikasikan poduk dan jasa kepada konsumen. Untuk mengurangi kecemasan mengenai resiko dalam menggunakan jasa perbankan, para nasabah lebih merasa nyaman apabila mendapatkan informasi dari kerabat ataupun keluarga dekat mereka. Hal ini menggambarkan semakin positif informasi word of mouth yang diterima oleh nasabah maka akan semakin meningkat juga jumlah nasabah yang menabung pada BRI S Parman Bengkulu.

\section{Pengaruh ekuitas merek dan word of mouth terhadap keputusan nasabah} untuk menabung di Bank BRI cabang s. Parman Bengkulu

Dari hasil uji statistik yang dilakukan di ketahui bahwa $F_{\text {hitung }}$ sebesar 80,075 dan $\mathrm{F}_{\text {tabel }}$ sebesar 3,09. maka disimpulkan bahwa variabel ekuitas merek dan word of mouth secara bersama-sama mempengaruhi variabel keputusan menabung. Hal ini di artikan bahwa ekuitas merek yang dibangun dapat dipengaruhi dengan beberapa orang atau kelompok yang didalamnya melakukan komunikasi dan berinteraksi. word of mouth yang dibagun dari interaksi antar nasabah akan mempengaruhi keputusan menabung pada Bank BRI S. Parman Bengkulu. 


\section{SIMPULAN}

Berdasarkan hasil Penelitian dan analisis data maka dapat ditarik kesimpulan sebagai berikut :

1. Ekuitas merek memiliki pengaruh yang signifikan terhadap keputusan menabung pada Bank BRI S. Parman Bengkulu, dimana di peroleh $t_{\text {tabel }} 1,997<t_{\text {hitung }} 10,221$ dari hasil tersebut keputusan yang dapat diambil yaitu menolak $\mathrm{H}_{\mathrm{o}}$ dan menerima $\mathrm{H}_{\mathrm{a}}$.

2. Word of mouth (WOM) memiliki pengaruh terhadap keputusan nasabah menabung di Bank BRI S. Parman Bengkulu di mana diketahui bahwa $t_{\text {tabel }} 1,997<\mathrm{t}_{\text {hitung }} 8,542$ dari hasil tersebut keputusannya yang dapat diambil yaitu menolak $\mathrm{H}_{\mathrm{o}}$ dan menerima $\mathrm{H}_{\mathrm{a}}$.

3. Ekuitas merek dan word of mouth berpengaruh terhadap keputusan nasabah untuk menabung di Bank BRI cabang s. Parman Bengkulu, di ketahui bahwa $F_{\text {hitung }}$ 80,075 $>F_{\text {tabel }} 3,09$.

\section{Saran}

Berdasarkan hasil penelitian, maka penulis memberikan saran sebagai berikut :

1. Bagi pihak Bank BRI S Parman Bengkulu diharapkan untuk selalu menjaga ekuitas merek dari setiap nasabahnya karena nasabah merupakan asset bagi perusahaan.

2. Bagi penelitian selanjutnya diharapkan dapat meneliti variabel-variabel lain di luar variabel ini agar memperoleh hasil yang lebih bervariatif yang dapat menggambarkan hal-hal apa saja yang dapat berpengaruh terhadap keputusan nasabah menabung.

\section{DAFTAR PUSTAKA}

Arya Nugraha Suryaatmaja, Ni Wayan Sri Suprapti, dan Ni Nyoman Kerti Yasa. (2016). Pengaruh Kualitas Layanan dan Citra terhadap Kepuasan dan Word of Mouth Nasabah . E-jurnal Ekonomi dan Bisnis Universitas Udayana.Vol 5 No 7.Pp 21912210.

Assauri, S. (2018) Prosedur Penelitian suatu pendekatan praktik, Jakarta :Rineka Cipta Astuti dan I Gede Cahyadi. (2007). Pengaruh Elemen Ekuitas Merek Terhadap Percaya Diri Pelanggan di Surabaya Atas Keputusan Pembelian Sepeda Motor Honda. Majalah Ekonomi.Tahun XVII No.2. Hal: 142.Agustus, Universitas Airlangga: Surabaya.

Ferdinand, Augusty. (2006) Metode Penelitian Manajemen: Pedoman Penelitian untuk skripsi, Tesis dan Disertai Ilmu Manajemen. Semarang: Universitas Diponegoro

Ghozali, Imam. (2012). Aplikasi Analisis Multivariat dengan Program SPSS. Semarang : Badan Penerbit Universitas Diponegoro.

Kotler, P\&Keller.L.K. (2016)Manajemen Pemasaran (EdisiGlobal). Edisi ke15, Jakarta: Erlangga.

Rangkuti,F. (2014). Strategi Promosi yang Kreatif. Jakarta: GramediaPustaka

Rodriges, Paula. (2015). Perceptual and Behavioral Dimension Measuring Brand Equity Consumer Based. Journal of Fashion Marketing and Manajement : An International Journal 20 (40) Retrieved.

Sanusi, Anwar. (2011). Metodologi Penelitian Bisnis. Jakarta: Salemba Empat.

Sernovitz,G ( 2017) The Powerof Word Of Mouth Marketing, NewYork: Amacom.

Simamora, Bilson. (2003). Aura Merek: 7 Langkah Membangun Merek yang Kuat. Jakarta: Gramedia Pustaka

Solomon, M. R. (2017). Consumer Behavior: Buying, Having and Being Edisi11. NewJersey : Prentice-Hall.

Sugiyono. (2004). Metode Penelitian Bisnis. Alfabeta, CV. Bandung 
Sugiyono. (2013). Metode Penelitian Pendidikan Pendekatan Kuantitatif, Kualitatif, dan $R \& D$. Bandung: Alfabeta.

Supranto dan Limakrisna, Nandan.(2011). Perilaku Konsumen dan Strategi Pemasaran. Edisi Kedua. Jakarta: Mitra Wacana Media.

Tjiptono, Fandy. (2004), Strategi pemasaran. Edisi Kedua. Yogyakarta: Penerbit Andi.

Tjiptono, Fandy. (2005), Strategi Pemasaran. Edisi Pertama. Cetakan Pertama. Yogyakarta: Penerbit Andi 